\title{
Eye opener: exploring complexity using rich pictures
}

\author{
Sayra Cristancho
}

Published online: 7 May 2015

(C) The Author(s) 2015. This article is published with open access at Springerlink.com

\begin{abstract}
Historically, approaches to exploring complexity have mainly focused on the notion that complex problems must be deconstructed into simpler parts if we are to make sense of them; this is the so-called reductionist approach. When dealing with the complexity of human experience, however, deconstructing the experience without diminishing it is a daunting, perhaps impossible task. Researchers wishing to make sense of complex experiences often begin by interviewing the individuals at the centre of those experiences. But interviews can be frustratingly limited. Visual methods, such as drawings, are beginning to show promise for designing research that taps into the complexity of professional practice. The promise of visual methods may relate to a key notion in complexity research: 'disruptions'. In this paper I introduce the notion of 'disruptions' as articulated by complexity approaches from 'systems engineering' and suggest 'rich pictures' as an effective visual method to describe and understand complex problems in medical education research.
\end{abstract}

\section{Keywords Complexity · Disruptions · Rich Pictures}

Long before we learn to write, we begin to draw pictures. As children, we draw about anything and everything: family, vacations, favourite foods, animals, etc. When was the last time you drew like that? For most of us, it was a long

S. Cristancho $(\square)$

Centre for Education Research \& Innovation and Department of Surgery, Health Sciences Addition, Schulich School of Medicine and Dentistry, Western University,

Room 110B, N6A 5C1 London, Ontario, Canada

e-mail: Sayra.Cristancho@schulich.uwo.ca time ago-probably when we were still children. That was certainly the case for me until recently.

Ten years ago I came to Canada to pursue my PhD. My first day at school was nothing close to what I was anticipating. It was definitely exciting to feel the atmosphere of a research-intensive North American university while walking through the beautiful campus. However, there were clouds, very dark clouds that suffocated me right from the first day at school: not being able to communicate as effectively as I used to in my own language, feeling so far away from home, feeling academically lacking and socially awkward. One day, I found myself drawing about these experiences (Fig. 1), and as I drew I realized the impact those clouds had had on my academic performance and professional identity. I found myself wondering about how other people had managed to cope with all these new challenges: how did they manage to navigate the complexity of the new environment? What did they lose and what did they gain? How did they think about themselves while immersed in such complex situations?

Complexity-particularly how people navigate the complexity of their professional practice-is the focus of my research programme. Historically, approaches to exploring complexity have mainly focused on the notion that complex problems must be deconstructed into simpler parts if we are to make sense of them; this is the so-called reductionist approach $[1,2]$. When dealing with the complexity of human experience, however, deconstructing the experience without diminishing it is a daunting task.

As a complexity researcher trained within the 'systems engineering' paradigm [3, 4], I find the reductionist approach helpful but problematic at the same time. It is helpful in trying to get an idea of the kinds of forces (i.e., complexity dimensions) involved in a situation, but it becomes problematic when trying to understand how those multiple 


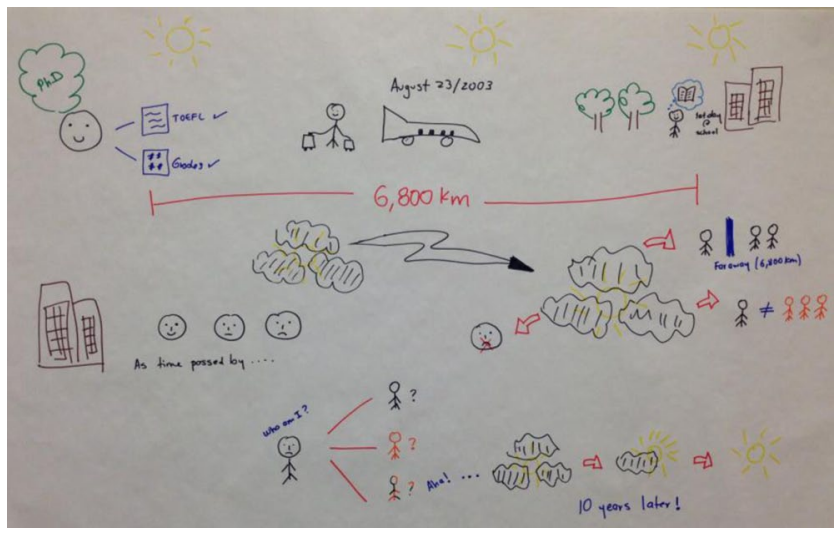

Fig. 1 Drawing the complexity of personal experiences

forces shape the evolution of the situation itself $[2,5]$. In trying to get at the dynamic, fluid and constantly changing nature of complexity, a holistic approach is required.

In the 'systems thinking' literature, a holistic approach involves: '(1) viewing a situation as a set of diverse interacting elements within an environment; (2) recognizing that the relationship or interactions between elements is more important than the elements themselves in determining the evolution of the situation; and (3) accepting, especially in social systems, that people will act in accordance with differing purposes' [6]. Drawing on these principles, I locate my research programme on complexity within an interpretivist perspective, where the goal is to understand the motives, meanings, and reasons in how individuals perceive and describe the complexity of their professional practice [7]. This understanding is time- and context-bound; for instance, what makes a surgical operation complex changes from day to day due to technical, personal, social and organizational factors. Therefore coming up with a single definition of 'surgical complexity' would be unrealistic. Understanding how each situation represents and contributes to a surgeon's way of adapting to complexity becomes a more fruitful endeavour from an educational point of view.

Researchers wishing to make sense of complex experiences often begin by interviewing the individuals at the centre of those experiences. As I have demonstrated elsewhere [8], health care professionals may struggle to articulate their experience in words, and may resort to describing only one aspect of the situation, even though they know there is more to it. They may also simplify their accounts of the situation by describing the 'easy-to-tell stuff' (e.g., the doing of a task) while backgrounding the 'difficult-to-tell stuff' (e.g., the emotional impact on themselves). Visual methods, such as drawings, in combination with interviews, are beginning to show promise for designing research that taps into the difficult-to-tell, by exploring tacit knowledge and perceptions of complex situations in professional practice [9-11]. My argument is not against the interview method, but rather for the productive usefulness of combining research methods that, by their nature, tap into different cognitive resources of an individual. In my research, while interviews (i.e., words) set the stage for the technical context of the professional activity, drawings allow participants to depict in detail the personal, social and organizational context of such activity. Research participants have referred to this approach of combining words and pictures as an effective way to foster 'big picture thinking' around a particular situation.

The promise of visual methods may relate to a key notion in complexity research: disruptions. Disruptions are game changers: events that transform our way of seeing and thinking about a situation. Looking for disruptions allows a more dynamic, contingent and situated understanding within and across complex situations [12,13]. But disruptions are not something that people easily identify when immersed in a complex situation; because disruptions occur when different forces affecting a situation clash, they are not normally observed but felt. Faced with this challenge, a complexity researcher needs tools that illuminate, or even create, disruptions. For example, if we ask a participant to describe their stories using a different method from interviews, we disrupt their way of thinking about their experiences, and may gain new insights as a result-visual or arts-based methods are particularly effective in this regard. At the same time those new insights from one individual may become disruptions for another (e.g., a researcher or another participant in the situation), shaping the interpretation of the situation in a different, likely unexpected, but usually deeper form.

While reinterpreting my drawing exercise using a researcher's perspective, I quickly realized that the type of drawing I was doing about my personal experience was, in fact, a visual tool that is used extensively in systems engineering. Such tools, called 'rich pictures', are used to describe and understand complex problems [5]. In recent efforts to get at both what can be observed and what can only be felt, we have incorporated rich pictures to study experts' experiences in coping with complex situations $[8,10]$. We have found that when we ask experts to draw about their experiences, we can often more readily identify disruptions, such as the impact of the human experience when practising in high-stakes professions. Furthermore, the very experience of drawing creates a disruption that can allow not only a complex situation to be viewed by both researcher and participant from a fresh perspective, but also to reflect more deeply in relation to previously encountered situations.

A rich picture is both a tool for understanding and a space to support dialogue [14]. Rich pictures may help researchers develop a multiple perspective understanding within and across messy or complex situations [15]. As pictorial representations, rich pictures attempt to capture a perspective of a 'reality' with all its interacting components-things, ideas, people, character, feelings, beliefs, conflicts. Using 'stick 
figures', they show features of interest and the interactions between them. Rich pictures allow individuals to tell their story, therefore constituting a way of understanding how individuals see their place and role in relation to the situation [16].

In our experience studying surgical complexity, rich pictures have allowed surgeons to represent, through visual metaphors, complex operations in ways they could not do in words. For example, we realized that trust was a major factor influencing the evolution of a complex operation only after one of our participants drew about it in the form of the William Tell analogy: apples on the heads of the surgeon, the patient and the resident joined by red arrows. The surgeon went on to acknowledge that it did not occur to him to talk about trust as a complexity dimension before drawing the picture; through drawing, he realized that in his mind there was more than the technical and the communication dimensions playing a role in that particular operation.

Rich pictures turn our attention to additional ways of representing experiences besides words. Colour, position, size, complexity, tone, directionality, and implied motion add to the conversation by helping us to think more holistically and directing our attention not only to what is included in them but also to what is omitted [17]. In the research context, rich pictures may serve as facilitators of dialogue between participants and researchers. The reciprocity and resonance that are built during the interpretation of the pictures help both participants and researchers engage in a very important task of dealing with complex situations: spending enough time understanding the problem before rushing into solving it [3]. While rich pictures may offer a space for dialoguing, their aesthetic value (i.e., what is drawn and how it is drawn) complements words [8]. In this way, rich pictures may stimulate reflective conversations, provide a focus to enrich an interview, or provide data points themselves to be understood through aesthetic analysis. This complementarity may be useful when uncovering the tacit dimensions, the emerging patterns and the disruptive forces of a situation as seen by expert clinicians [10].

Medical education is a messy field in which the experiences of our trainees and faculty happen in contexts where everything is connected with and influenced by everything else-the disease's characteristics, the patient's social situation, the institutional constraints, the physician's professional and educational goals, and the learner's personal challenges. Rich pictures constitute a valuable research tool to depict a situation from multiple angles or perspectives, to make visible the disruptions among those perspectives and to co-construct meaning about them.

Funding N/A.
Notes to contributors Dr. Sayra Cristancho conceptualized, designed and wrote the entirety of this manuscript.

Acknowledgments The author would like to thank Dr. Chris Watling for his valuable comments and insights during the preparation of this manuscript.

Open Access This article is distributed under the terms of the Creative Commons Attribution License which permits any use, distribution, and reproduction in any medium, provided the original author(s) and the source are credited.

\section{References}

1. Davis B, Sumara DJ. Complexity and education: inquiries into learning, teaching, and research. Mahwah: Psychology Press; 2006.

2. Stacey RD, Griffin D, Shaw P. Complexity and management: fad or radical challenge to systems thinking? New York: Psychology Press; 2000.

3. Cristancho S, Regehr G. From problem-solving to problem-definition: conceptualizing expert judgment through the lens of systems engineering. (submitted).

4. Cristancho S. What can we learn from a soft sister? A complementary lens to the systems engineering approach in medical education research. Med Educ. 2014;48:1139-41.

5. Checkland P. Soft systems methodology: a thirty year retrospective. Sys Res Behav Sci. 2000;17:S11-58.

6. Mingers J, White L. A review of the recent contribution of systems thinking to operational research and management science. Eur J Oper Res. 2010;207:1147-61.

7. Cassell C, Symon G. Essential guide to qualitative methods in organizational research. London: Sage; 2004.

8. Cristancho S, Bidinosti S, Lingard L, Novick R, Ott M, Forbes T. Seeing in different ways introducing "rich pictures" in the study of expert judgment. Qual Health Res. 2014;25(5):713-25.

9. King N, Bravington A, Brooks J, Hardy B, Melvin J, Wilde D. The pictor technique a method for exploring the experience of collaborative working. Qual Health Res. 2013;23(8):1138-52.

10. Cristancho SM, Bidinosti SJ, Lingard LA, Novick RJ, Ott MC, Forbes TL. What's behind the scenes? Exploring the unspoken dimensions of complex and challenging surgical situations. Acad Med. 2014;89:1540-7.

11. Guillemin M. Understanding illness: using drawings as a research method. Qual Health Res. 2004;14:272-89.

12. Fenwick T, Edwards R, Sawchuk P. Emerging approaches to educational research: tracing the socio-material. New York: Routledge; 2011.

13. Martin AD, Kamberelis G. Mapping not tracing: qualitative educational research with political teeth. Int J Qual Stud Educ. 2013;26:668-79.

14. Berg T, Pooley R. Rich pictures: collaborative communication through icons. Syst Pract Action Res. 2013;26:361-76.

15. Bronte-Stewart M. Regarding rich pictures as tools for communication in information systems development. Comput Inform Syst. 1999;6:85-104.

16. Armson R. Growing wings on the way: systems thinking for messy situations. Devon. Triarchy Press Limited; 2011.

17. Bell S, Morse S. How people use rich pictures to help them think and act. Syst Pract Action Res. 2013;26:331-48. 
Sayra Cristancho is assistant professor, Department of Surgery, and scientist, Centre for Education Research \& Innovation, Western University, Canada. Her research programme investigates the organizational, social and personal factors that determine the evolution of complex clinical situations and their influence on clinical judgment. Towards this end, she follows Qualitative and Systems Engineering approaches to research. 